\title{
An Overview of the Translation and Introduction of "Liaozhai Zhiyi"' in the English World
}

\author{
Yanan $\operatorname{Jin}^{1}$ \\ ${ }^{1}$ College of Water Science, Beijing Normal University, Beijing, 100875, China \\ Corresponding author. Email: 1159203809@qq.com
}

\begin{abstract}
"Liaozhai Zhiyi" is known as the peak of ancient classical Chinese novels. The narrative is close to the folk. The protagonists, with strong folk customs, are principally from the bottom of the society, which reflects the religious concepts, folk beliefs, magic and folk culture of ancient Chinese society. Since the 1840s, this book had been translated many times into English and other languages. Taking the English versions of "Liaozhai Zhiyi" as the research object, this paper describes the transmission course and track of "Liaozhai Zhiyi" in the English world, which is conducive to understanding the translation and dissemination of Chinese cultural classics in the English world.
\end{abstract}

Keywords: Liaozhai Zhiyi, English world, translation and introduction

\section{INTRODUCTION}

"Liaozhai Zhiyi" is hailed as the pinnacle of ancient classical Chinese collected short stories. Its narrative is close to folk life, and the protagonists are mainly at the bottom of the society, containing a strong folk atmosphere. Thus, it is an important window for English readers to know Chinese secular culture. Lu Xun once said that it was "the most famous anthology" [5]; Ma Ruifang once remarked," $\mathrm{Pu}$ Songling pushed up an insurmountable peak of short stories" [6]. Compared with Four Books and Five Classics, Journey to the West, Romance of the Three Kingdoms, Water Margin, Dream of the Red Chamber and other ancient classics, Liao Zhai Zhi Yi has extensive subjects, rich genres, shorter length and diversified materials and its content is closer to people's daily life. Therefore, it is undoubtedly one of the main classics of Chinese culture going out.

The English translation of Liaozhai Zhiyi has a long history, which indicates that it is extremely attractive to English-speaking readers. Although the high sales is a reason why translators keep translating this book, it can alsoindicate that the former translations have their own advantages and disadvantages, attracting subsequent translators to keep upgrading. This paper summarizes the translation process of Liaozhai Zhiyi in the English world, hoping to be of some value to future researches.

\section{AN OVERVIEW OF ENGLISH TRANSLATIONS OF LIAOZHAI ZHIYI}

Liaozhai Zhiyi entered the English-speaking world at the beginning of 1842. Many scholars translated Liaozhai Zhiyi into English, and the number of translated articles varied greatly: some translator translated more than 500 articles while some only finished half a story. There are many articles scatteringly published in periodicals, magazines or related books, and many articles collected and published in one books. For the convenience of writing, the author classifies them all according to translators regardless of sources and origins, which called XX translation version such as Samuel Wells Williams' translation. It can be seen from the translation of "seng( 僧)” in various versions that Rose Quong's translation and the subsequent versions often adopt the translation method of foreignization and focus on introducing the Chinese culture while the previous translations always applied the translation method of domestication to cater to the English world readers. Therefore, they can be divided into the early and late translations.

\subsection{Early Translations}

In 1842, the German missionary Karl Friedrich August Gutzlaff (1803-1851) published an article Liáu Chái Í Chi, or Extraordinary Legends from Liáu Chái (hereinafter referred to as Gutzlaff's translation) to introduce Liaozhai Zhiyi in Chinese Repository, Vol.11, 
Issue.4, which including nine stories. In the same year, American missionary Samuel Wells Williams (18121884) selected 17 stories of Liaozhai Zhiyi in his Chinese study textbook Easy Lessons in Chinese, in which three stories were translated into English and are in accordance with English habits, including Planting Pears, CaoCao's Tomb and Swearing Duck1. And Planting Pears and Swearing Duck were later included in his book The Middle Kingdom published in 1848. In addition, Chinese Repository Vol.18, Issue.8 (August 1949) also included Shang Sanguan translated by Williams. It is not yet clear who was the first to translate Liaozhai Zhiyi.

In 1867, William Fredrick Mayers (1831-1878), a British diplomat in China, introduced Liaozhai Zhiyi and $\mathrm{Pu}$ Songling to English readers and translated the first half of The Drinking Friends on the first issue of Notes and Querries on China and Japan published in Hong Kong.

Between 1874 and 1875, Clement Francis Romilly Allen (1844-1920), British diplomat and sinologist, published the translations of 18 stories of Liaozhai Zhiyi under the title Tales from the Liaozhai Zhiyi in the magazine of China Review or Notes and Querries on the Far East issued in Hong Kong. The magazine was the most influential English-language journal in the Far East at that time, so Allen's translation played a significant role in the spread of Liaozhai Zhiyi in the English world.

In 1877, the renowned English sinologist Herbert Allen Giles (1845-1935) delivered his translation of Luoshahai City in the first issue of Celestial Empire, which was the beginning of his translation of Liaozhai Zhiyi. In 1880, Thos. de la Rue in London published two volumes of Giles' translation of Strange Stories from a Chinese Studio, containing 164 stories with massive annotations about Chinese culture. This translation is the most influential one in the English world. After that, it was reprinted several times. In 1989 and 1994, Heian International Inc. in America selected some of the translations and published Strange Tales from Ancient China and More Strange from China respectively.

In 1894, Yangon Dewaz Publishing House published J. A. Maung Gyi and Tun lun Hsieh's English translation of Liaozhai Zhiyi named The Celestial Mirror, which consists of 24 stories. The book also contained several stories about Bao Gong Case.

In 1907, Walter Caine Hiller (1849-1927), a British diplomat, translated 13 stories of Liaozhai Zhiyi in his Chinese learning textbook The Chinese Language and How to Learn: A Manual for Beginners.

In 1913, George Soulie de Morant (1878-1955), a French diplomat and Sinologist in China, translated 25 stories of Liaozhai Zhiyi and published by the Houghton Mifflin Company, which was entitled as Strange Stories from the Lodge of Leisures. The translation was so different from the original texts so that it is difficult to find the corresponding Chinese stories.

In 1921, American sinologist Frederick Herman Martens (1847-1932) and German missionary and sinologist Richard Wilhelm (1873-1930) published The Chinese Fairy Book, which contained nine stories of Liaozhai Zhiyi they translated.

In 1922, Edward Theodore Chalmers Werner, (18641954), the British consul in China, compiled Myths and Legends of China, in which he rewrote five stories and included them in a chapter called Fox Legends. Once published, this book spread widely throughout the English-speaking world, contributing to the popularization of Chinese mythology, and later being reprinted for many times, it has become an important material for the study of Chinese mythological literature.

In 1927, the Russian Sinologist J. Brandt (1869-1944) compiled a translation of the Chinese learning textbook Introduction to Literary Chinese, which included five English translations of five stories in Liaozhai Zhiyi. The first edition of the book was published by North China Union Language School in Beijing, and then it was republished in 1936 and revised and published by the publishing house Frederick Ungar in New York in 1944. It remains a classic textbook for the English-speaking world to learn Chinese writing.

In 1929, Carlo De. Fornaro (1871-1949) translated George Soulie de Morant's Les contes gallants de la chine into The Chinese Decameron, which contained one story in Liaozhai Zhiyi: the Taoist Monk.

In 1933, Pan, Tze-yan translated A Crow Wife in Liaozhai Zhiyi and published in the 18th issue of China Journal of Science and Arts in Shanghai.

In 1937, the Chinese English phonetician and famous Chinese-English translator Chu Dagao (1898-1987) translated and published Stories from China in London, including three stories of Liaozhai Zhiyi. In the same year, Frances Carpenter (1890-1972) published his English story collection, Tales of a Chinese Grandmother, which contained three stories.

\subsection{Late Translations}

In 1946, Chinese-Australian artist and sinologist Kuang Rusi (1879-1972) translated Chinese Ghost and Love Stories published by Pantheon Books Inc. The book focused on sad and beautiful love stories.

In 1952, Lin Yutang selected 20 "Masterpieces of China's most Famous Short Stories" and translated them into English, named Famous Chinese Short Stories, which was published by the John A Day Company in the United States, then reprinted for several times. Some 
stories of this book became classics in American literature textbooks.

In 1956, Yang Xianyi and Dai Naidie co-translated five stories of Liaozhai Zhiyi published in the January issue of Chinese Literature. Then in 1962, they published three translatied stories of Liaozhai Zhiyi in the 10th issue of Chinese Literature. In 1981, these translations, along with other stories of their translation, were included in Selected Tales of Liaozhai.

In 1966, Yale University Press Far Eastern publications Series published Strange Stories from a Chinese Studio, a translation by Linda Hsia and Roger Yeu.

In 1976, the University of Oxford published Chinese Tales of the Supernatural with 16 stories of Liaozhai Zhiyi translated by Benjamin Chia.

In 1978, American Sinologist Jaseph S. M. Lau and Y. W. Ma compiled Traditional Chinese Stories: Themes and Variations. The book contained six stories from Liaozhai Zhiyi and they were divided into various themes: Nie Xiaoqian was included in the theme of the ghost wife, Taoist Priests in Laoshan was included in the theme of the faithless seeker, and Swordswoman was included in the theme of the Knight-Errant.In the same year, Christopher Levenson translated the German versions, known as Die Golden Trube of Wolfgang Bauer and Herbert Franke into English as The Golden Casket, and the last two stories in the book were Heng Niang and Ge Jin in Liaozhai Zhiyi.

In 1982, the Hong Kong Commercial Press published Strange Tales of Liaozhai, translated by Lu Yunzhong, Chen Tifang, Yang Liyi and Yang Zhihong, which contained 50 stories of Liaozhai Zhiyi. The revised edition added 34 tales in 1988.

In 1983, Columbia University Press published Chinese Literature 3: Tales of the Supernatural edited by H. C. Chang. The book takes in four stories of Liaozhai Zhiyi translated by H. C. Chang. Before the four stories, there was an article Liao-chai chih-i that introduced and analyzed Liaozhai Zhiyi, and each story is preceded by a brief introduction of the story's background and theme.

In 1988, Foreign Language Teaching and Research Press published Selected Translations by Pu Songling's Strange Stories of Liaozhai translated by Mo Ruoqiang, Mo Zunzhong and Mo Zunjun, which contained 20 tales of Liaozhai Zhiyi.

In 1989, Foreign Languages Press published Strange Tales from Make-do Studio translated by American sinologists Victor H. Mair and Denis C. Mair, which selected 51 stories of Liaozhai Zhiyi. The book was republished in 2005 by University Press of the Pacific (hereinafter referred to as Mairs' translation). In 2001, the Foreign Languages Press compiled and published 30 pieces from the translation, and included them in the
Classic Echoes series. In 2000, Victor H. Mair compiled and published The Shorter Columbia Anthology of Traditional Chinese Literature, which included three of their translation stories.

In 1991, Alex Page translated 16 articles from German sinologist Martin Buber's German translation of Liaozhai Zhiyi, being included in Chinese Tales: Zhuangzi, Sayings and Parables and Chinese Ghost and Love Stories.

In 1993, American sinologist, Judith. T. Zeitlin's Historian of the Strange: the Pu Songling and the Chinese Classical Tale contained four stories of Liaozhai Zhiyi translated by the author. After its publication, the book exerted a great influence in the English world and had become a classic work in the English world to study Liaozhai Zhiyi. Besides, Under Confucian Eyes: Writings on Gender in Chinese History, written by Susan and YuYin Cheng, included two other stories translated by Judith. T. Zeitlin.

In 1995, China Translation and Publishing Company published 100 Chinese Myths and Fantasies translated by Ding Wangdao, which contained 10 stories of Liaozhai Zhiyi. Yenna Wu translated Ma Jiefu and published it in the 43rd issue of Renditions the same year. Four stories were later translated and together included in The Lioness Roars: Shrew Stories from Late Imperial China, published in 1995 by Cornell University Press. Yenna Wu tended to translate stories in which women had a higher status. Jeanette Faurot is the author of Asian-Pacific Folktales and Legends, which contained his own translation of Painted Skin. In 2008, Chia-Jung Cheng cited the translation in his doctoral dissertation The Painted Skin.

In 1996, Tzelan Deborah Sang translated Feng Sanniang in his doctoral thesis The Emerging Lesbian: Female Ssme-Sex Desire in Modern Chinese Literature and Culture. Stephen Owen selected and translated three stories of Liaozhai Zhiyi: Lian-xiang, Xiao-cui and Blue Maid in his book An Anthology of Chinese Literature: Beginning to 1911 the same year.

In 1997, the China People's Publishing House published three volumes of Strange Tales from the Liaozhai Studio, containing 194 stories of Liaozhai Zhiyi. The three volumes are translated by different translators and reviewed by diverse people. Among them, the first volume was translated by Zhang Qingnian, Zhang Ciyun, Yang Yi, and reviewed by Martha Graham.

In 1998, Wang Juan translated 100 Passages from Strange Stories of Liaozhai, including 51 stories of Liaozhai Zhiyi.

In 2003, Michael Bedard translated The Painted Wall and Other Strange Tales, which included 23 stories of Liaozhai Zhiyi. The translator referred to the translations of Herbert Allen Giles, Kuang Rusi and Yang Xianyi and Dai Naidie, mainly for teenagers. 
In 2005, Sing-chen Lydia Chiang published Collecting the Self: Body and Identity in Strange Tale Collection of Late Imperial China, including Jiaer translated by the author.

In 2006, Professor John Minford, who had translated Dream of Red Mansions with David Hawks, compiled Strange Tales from a Chinese Studio, which contained 104 stories. The book is accompanied by 63 pages of notes.

In 2007, China Foreign Languages Press published a four-volume edition of Selections from Strange Tales from the Liaozhai Studio, included in Great China Library (Chinese-English bilingual) with 216 stories in Liaozhai Zhiyi. The book is based on Zhang Youhe's revised version in Chinese. The English translations mainly adopted the translations of Huang Youyi, Zhang Qingnian, Zhang Ciyun, Yang Yi, Victor H. Mair and Denis C. Mair.

In 2008, Song Deli, a Chinese American, compiled a Chinese-English bilingual book of Strange Tales of a Lonely Studio, including 20 stories of Liaozhai Zhiyi.

In 2008, the American Sinologist Sidney L. Sondergard translated Strange Tales from Liaozhai published by Jain Publishing Company and by 2014, all six volumes had been published. The book is the first and only full translation of Liaozhai Zhiyi.

\section{A BRIEF STUDY ON THE ENGLISH TRANSLATION OF LIAOZHAI ZHIYI}

Since the first English translation in the mid-19th century, there have been more than 40 translations so far, and the English translations have had the greatest influence in the world. The translation studies on Liaozhai Zhiyi at home and abroad are relatively late and insufficient. Domestic researches on Liaozhai Zhiyi can be divided into four aspects: English translation history study, case study, multi-translation comparative study and translators study.

(i) Wang Lina [11] made a diachronic description of the English translations of Liaozhai Zhiyi, and claimed that Williams' translations of Planting Pears and Swearing Duck in 1842 are the earliest translations, while Wang Yan [12] considered the earliest translations to be Gutzlaff's translation in Chinese Repository in 1842, and Ren Zengeng [8] also verified Karl Friedrich August Gutzlaff as the first person of "Liao Zhai Xi Chuan" from the perspective of Sinology. It can be seen that the translation history of Liaozhai Zhiyi still needs to be supported by historical materials. In addition to the study of the early history of translation, He Min [3] studied the English translation history of Liaozhai Zhiyi from two aspects: the translators and translations of cultural recipient countries and translators and the translations of cultural exporters in the form of important transcripts and excellent episodes translations. Unfortunately, limited by the length, it merely analyzed part of the translations. On the basis of historical data, Zhu Zhenwu [16] gave a diachronic description of the 100-year English translation of Liaozhai Zhiyi before 1949.

(ii) The case study of the translation of Liaozhai Zhiyi primarily discussed the translation strategies of foreignization or domestication from the perspective of culture, the translator's identity or translation purposes. $\mathrm{Li}$ Haijun [4] expounded the translation strategies adopted by different translations, sorting the process from cultural manipulation to cultural integration; Sun Xueying [9] studied the mistranslation of culture-loaded words and the translator's style from the perspective of hermeneutics. This illustrated that the cultural and hermeneutic perspectives based on the philosophy of language interpretation can provide some guidance for translation activities; Zhu Zhenwu [16] explored the rationality of "misreading" in Giles' translation under the restriction of cultural context and other hypertext factors. Moreover, translation studies on Liaozhai Zhiyi in the perspective of comparative culture had emerged, such as Sun Yimin [10], evaluating translation strategies and subtexts of Giles' translation. However, in the above case studies, Giles' and Mairs' translations were mostly used, so it's hard to see the translation criticism of other translations, which makes the value of evaluations of the translations limited.

(iii) The comparative study of the translations is mainly based on Giles' and Mairs' translations, and the translations of John Minford and Yang Xianyi are equally popular. Furthermore, there was a comparison of annotations between Russian and English translations [13]. He Jin [2], based on the theory of functional translation, analyzed and compared Giles' and Mairs' translations to evaluate Giles' translation and its purposes; Wang Yunhong [14] made a case study of the translation of words in three translations to study the relationship between his translation strategies and social and cultural contexts.

(iv) Translators study focused on the background and identity of translators, such as Ren Zengqiang studied the translation of several well-known sinologists from the perspective of overseas Sinology through the background and identity of translators, such as Rose Quong stressing the relationship between the identity of female and theatrical performers and her translations.

There are not many studies on English translation abroad. John Minford \& Tong Man affirmed Giles' translation in their papers, focusing on the rewriting of Giles' translation. Pei Yongming [7] adopted the method of corpus to study the differences in the selection and translation methods of various versions of Liaozhai Zhiyi from the perspective of subtext. There are also a few book reviews, translator's own narrations and researches of Liaozhai Zhiyi within the scope of sinology or sinology. 
Allan Barr's dozens of Chinese papers focus on the source of stories, the way of expression and the style of style, and study the identity of outlier women in Liaozhai Zhiyi; Judith Zeitlin [15] pays attention to gender identity in Liaozhai Zhiyi; Chiang, Sing-chen Lydia [1] is interested in body and identity issues. In the history of translation of Liaozhai Zhiyi, there are plenty of high-quality translations, so many sinologists have used ready-made translations as their research objects, but with the development of sinology or Chinese studies, more and more interdisciplinary research methods and new theoretical paradigms are applied. Thus ready-made translations usually are unable to meet the needs of researchers; many researchers choose to translate by themselves, such as Judith Zeitlin and Chiang, Sing-chen Lydia. The sinologist's study on Liaozhai Zhiyi will undoubtedly deepen the understanding of the Chinese culture in Liaozhai Zhiyi in the western world. However, most of the translated works by sinologists have their own identity characteristics, so it is difficult to be objective and comprehensive.

In general, the study of English translation of Liaozhai Zhiyi has the following characteristics: [i] From the perspective of the versions of translations, most of them are focused on Herbert Allen Giles', Victor H. Mair and Denis C. Mair', Yang Xianyi' and John Minford' translations. The reasons are obvious: firstly, these translations have a wider influence, thus more documents and materials found. Secondly, as other translations have a longer history (such as Gutzlaff's and Williams' translations) and less circulation (such as J. A. Maung Gyi and Tun lun Hsieh's translation of The Celestial Mirror in 1894), it is difficult to find the original texts. [ii] From the perspective of the articles, most of them focus on famous articles, such as Kao Cheng Huang, Lian Xiang, Tong Ren Yu, Nie Xiaoqian, etc. Studies starting with a certain topicand furthurly discussing each article of the same topic systematically are few. [iii] From the perspective of the research conclusions, there are more people who stop at the introduction and interpretation of specific translation strategies (such as domestication or foreignization), and fewer who extract the factors that may affect the options of translation strategies.

\section{CONCLUSION}

According to the translation time and the main translation strategies of Liaozhai Zhiyi in the English world, this paper has divided these tramslations into two stages, which is convenient to describe. But there is still a long way to go before the translation review, the analysis of the current research status of the English translation of Liaozhai Zhiyi is just a generalization, and there is still a lot of room for further research. The circulation and influence of Liaozhai Zhiyi translations vary greatly. The existing English translations and their research achievements are quite rich, but there are also some shortcomings.Liaozhai Zhiyi The author contends that the attention paid to the translation and research of cultural classics is not enough. Taking Liaozhai Zhiyi as example, researches on its translations, articles and translation theories are of a single type. In addition, translation studies should not only focus on the text itself, but also need to stand beyond linguistic level, look at the translations from disciplines outside the field of translation and pay attention to the details beside the translation process. In a word, the study of Chinese culture going out and translation of ancient classics remains in the stage of exploration, and it is still a long way from the complete theoretical system.

\section{REFERENCES}

[1] Chiang, Sing-chen Lydia. Collecting The Self: Body and Identity in Strange Tale Collection of Late Imperial China. Leiden: Brill Press, 2005.

[2] He Jin: On Giles' Translation of Liao Zhai Zhi Yi From the Function Theory, Guangdong University of Foreign Studies, 2004.

[3] He Min: A Review of Translation of Liao Zhai Zhi $\mathrm{Yi}$ in the English World, Foreign Language Teaching and Research, 2009, 2: 148-152.

[4] Li Haijun: From Cross-cultural Manipulation to Cultural Integration--English Translation Studies on Liao Zhai Zhi Yi, Shanghai Foreign Studies University, 2011.

[5] Lu Xun: A History of Chinese Novels. Nanning: Guangxi People's Publishing House, 2017.

[6] Ma Ruifang: From Liao Zhai Zhi Yi to Dream of the Red Chamber. Jinan: Shandong Education Press, 2004.

[7] Pei, Yongming. Re-Presenting China through Retransaltion-A Corpus-Based Study of Liaozhai Zhiyi. Ann Arbor: Kent State University, 2018.

[8] Ren Zengqiang: Dreams and Fictions: On Translation of Liao Zhai Zhi Yi by American Sinologist Judith. T. Zeitlin, Study on Pu Songling, 2018, 2: 87-99.

[9] Sun Xueying, The Translation Study of Liao Zhai Zhi Yi Under the Perspective of Hermeneutics, Shanghai International Studies University, 2014.

[10] Sun Yimin: Notes on the Translation of Liaozhaizhiyi Xuan by Giles and the Reception of the Translation [J], Studies of Fiction in the Ming and Qing Dynasties, 2007, (2):228-237.

[11] Wang Lina: The Classic Chinese Novels and Operas abroad. Shanghai: Xuelin Publishing House, 1988. 
[12] Wang Yan: On the First Translation of Liao Zhai Zhi Yi in the West, Research on Novels of Ming and Qing Dynasties, 2008, 88:214-226.

[13] Wang Ye, Yan Guodong: A Comparative Study of Russian and English Translations in Liao Zhai Zi Zhi, Russian Literature and Arts. 3 (2017): 122-129.

[14] Wang Yunhong: The choice of translators or history-- A Case Study of the Translation of Liao Zhai Zhi Yi[J]. Journal of Chendu College of Education, 2005 (10): 100-101.

[15] Zeitlin, Judith T. Phantom Heroines: Ghosts and Gender in Seventh-century Chinese Literature and Beyond. Honolulu: University of Hawaii, 2007.

[16] Zhu Zhenwu, Yang Shixiang, Liao Zhai Zhi Yi after the founding of the People's Republic of China, Study on Pu Songling, 2016, 1: 69-80. 